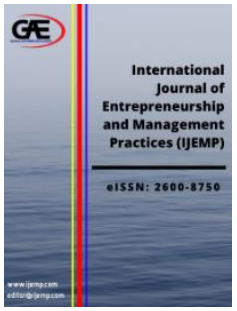

\author{
INTERNATIONAL JOURNAL OF \\ ENTREPRENEURSHIP AND \\ MANAGEMENT PRACTICES \\ (IJEMP) \\ WWW.ijemp.com
}

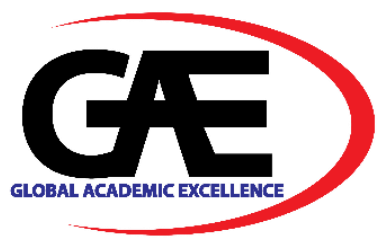

\title{
ENABLING EMPLOYMENT FOR PEOPLE WITH DISABILITY (PWD): READINESS, COMMITMENT, AND DISPOSITION OF MALAYSIAN EMPLOYERS
} \author{
Zakaria $^{5}$ \\ 1 Department of Science and Technical Education, Universiti Putra Malaysia \\ Email: khaizer@upm.edu.my \\ 2 Department of Science and Technical Education, Universiti Putra Malaysia \\ Email: shailaimatali@gmail.com \\ 3 Department of Science and Technical Education, Universiti Putra Malaysia \\ Email: hazwan@upm.edu.my \\ 4 Department of Science and Technical Education, Universiti Putra Malaysia \\ Email: mohamadyaakub@gmail.com \\ 5 Department of Science and Technical Education, Universiti Putra Malaysia \\ Email: anis@upm.edu.my \\ Corresponding Author
}

Muhd Khaizer Omar ${ }^{1}$, Nor Shailai Mat Ali², Mohd Hazwan Mohd Puad ${ }^{3}$, Mohamad Yaakub ${ }^{4}$, Anis

\section{Article Info:}

\section{Article history:}

Received date: 08.07.2021

Revised date: 30.07 .2021

Accepted date: 03.08.2021

Published date: 01.09.2021

\section{To cite this document:}

Omar, M. K., Mat Ali, N. S., Puad, M. H. M., Yaakub, M., \& Zakaria, A. (2021). Enabling Employment For People With Disability (Pwd): Readiness, Commitment, And Disposition Of Malaysian Employers. International Journal Entrepreneurship and Management Practices, 4 (15), 01-22.

DOI: $10.35631 /$ IJEMP.415001.

\begin{abstract}
:
People with disabilities (PWD) struggle with prejudices, narrow-mindedness, and maltreatment. This situation has brought many questions on how the public serves them. Concerning PWDs' employment, the source of income and the wellbeing of this community frequently be neglected and depreciated. The research issues a call to this agenda and suggests action to empower employment among PWD. Descriptive quantitative research was employed to 136 employers from various industries. This article reports three variables: readiness, commitment, and disposition of industrial players on hiring PWD. The results of the study describe that employers are more likely to hire PWD in their organization based on their readiness and commitment, however, the disposition was discouraging. The types of disabilities, industries and ethnicities of the PWD contribute to a major decision when hiring PWD. Employment of PWDs is afflicted by skeptical and dubious perspectives due to their capabilities and capacities to fulfill job responsibilities. With encouragement and empowerment of skilled development programs, PWD is supposed to be allowed to join the workforce, performing a job that suits their impairment. Ongoing support must be advocated among the grassroots of the nations that ultimately flourish the life of PWD.
\end{abstract}




\section{Introduction}

In recent years, there has been an increasing interest in research related to people with disabilities. Noting the contribution of People With Disability (PWD) and well-being has been questioned for many years, research provides ample evidence of PWD struggles and injustice of those people and community on the grounds. PWD is tormented by a virulent and skeptical perception of community reflected on those individuals who experience some form of disabilities. PWD accumulates over $15 \%$ of the world's population, numbered at one billion people (The World Bank, 2021) creates sensationalism, often extending a welcome of such controversial statements on how we treat them as human beings.

Approximately there are 61 million disabled people among adult people in the USA (CDC, 2020). This number resonates with the gruesome facts of those who fall under poverty and become homeless. PWD are subjected to ill-treatment and isolation by numerous entities due to their condition. It is also a pertinent fact that most PWD is unemployed causing long standing issues of their well-being and how they lead their life. According to the report from the U.S. Bureau of Labor Statistics, a proportion of only 17.9 PWD were successfully employed by industries in 2020. The issue of unemployment among PWD is evident in which this number decreased to $19.3 \%$ in 2019 (BLS, 2021). A report by the parliament of the UK regarding employed PWD in the workforce states that 4.4 million of them were successfully hired by various industries.

Information related to the number of PWDs in Malaysia described the proportion of percentage of those PWD with types of impairment. According to the department of social welfare in 2017, 453,258 people are categorized as PWD. PWD in the physical category recorded the highest number, which was 35.2 percent, followed by the Learning disability category (34.8\%) and the Visually impaired category (8.9\%). The speech category recorded the lowest registration of 0.5 percent (Department of Statistics Malaysia, 2020).

The Malaysian government has put forth to empower PWD in the employment market based on the PWDs action plan blueprint for 2016-2022. In this blueprint, the job market will be more accessible and comprehensive enough to ensemble the capacities and proficiency of this group. The job availability will be more transparent and open to PWDs. Attached to this initiative, skills and educational programs are provided from time to time to ensure PWDs be more independent and eventually would help them to earn a living. This whole idea is to prosper the human capital development of the nation as a whole (Wanita dan Masyarakat, 2016).

It is visible to claim that jobless PWDs are a long-extended issue. Based on the media report from the statement of the Ministry of Women, Family and Community Development in 2019, the number of PWD employees in the government agencies stood at 3,856 (0.31\%). This number is a proportion of the total of $1,268,701$ public government sector employees. Nevertheless, the government has sally forth of PWD employment through the ruling of $1 \%$ job opportunities in government agencies (Wanita dan Masyarakat, 2016). This relatively imposes the hiring opportunities for PWDs in the government sector. 
It is indeed important to conduct studies related to PWD employment as this will advocate industrial stakeholders to provide job opportunities to a disabled person. Therefore, the purpose of this research is to discover the crucial reasons for determining PWDs' hiring factors. Two research objectives were developed: (a) to determine the level of readiness, commitment, and disposition of Malaysian employers on hiring PWD into their organization and (b) to determine the relationships among selected variables on PWD hiring factors. The aforementioned variables are excruciating factors in determining the chances of PWDs in acquiring jobs for the workforce.

\section{Literature Review}

Views in employment range of many aspects from the perspective of employers and the capabilities of PWD to deliver their job responsibilities. Suppose research related to PWD encouraged consensus between both parties in determining the middle-ground. Equally important, the proactive action from the grassroots level, must be systematically developed to empower PWD readiness to join the job market. Portraying from the psychological well-being of the PWD, it is indeed, this group tends to be deeply deprived of the whole life experience. Emerson et al (2020) measured the PWDs' well-being inventory and found that this community suffered many complicated issues that trigger negative drawbacks in their sociological and physiological well-being. Certainly, people are loath to deny the right of PWD to cherish life as a normal human being.

The primary factor toward PWD employment as suggested by Saidi et al (2018) was the working environment. They enunciated that PWDs encounter struggles to venture into the job market due to the unconducive workplace. Neglects and attitudes of employers trigger a challenge to most PWD in finding a job. As highlighted by Nicholas et al. (2019), the perceptions and reluctance of employers involving autistic individuals were evident. It is an anomaly for PWD to perform regular job responsibilities just like other people. They have a propensity for a specific task that suits their type of disability.

Additionally, the chances of PWD to join the workforce is emphasizing on strategy on fulfilling the specific job. Bezyak et al. (2020) found differences suggesting that disability participation strategies and recruitment objectives are essential in the purpose of recruitment. For example, policy from the government and policymakers in encouraging employers in PWDs to provide various benefits and incentives is one of the effective strategies. Nevertheless, it is difficult to allay the concern of employers about how susceptible PWD is to the specific task and how easily they succumb to the risk of being manipulated by other colleagues.

Numerous studies have attempted to explain significant factors that contribute to the disparity of PWD in the workforce. Unit (2005), for example, discovered that geographical and logistic factors of people with physical disabilities have become the major barrier for them to obtain employment and improve living standards. Similarly, Cohen et al. (2019) posited that time of task completion adding the encumbrance of PWDs in the job market as this would attenuate their chances of getting a job.

Despite the finding from Cohen et al. (2019), that employer perspective, especially with PWD with some form of mental illness, showed that employers consider more barriers to hiring people with disabilities who have intellectual disabilities and mental disorders than physical disabilities. Employment for this group is hampered by a lack of skills and legal issues. Cohen et al. (2019) again suggested that skeptical beliefs about disability can shape performance, 
participants in simulated disability situations can complete tasks more accurately than controls. All in all, having the right mindset and reducing negative connotations, the barrier to social participation specially to enter the labor market.

Following many proactive attempts in placing PWD in the job placement, the concurrent study delves into the important contribution of technology. Numerous assistive tools and apparatuses have been developed to assist PWD to perform myriad functions and responsibilities. Oware and Mallikarjunappa (2019) highlighted the need to integrate suitable technology to empower PWD in the job environment. In the finance and banking sector, Oware and Mallikarjunappa (2019) identified technological innovation as providing essential support for PWD. It is interesting to note that, of disabled employees with technological innovation, the firm's financial performance can be alleviated with minimal physical effort and voracious investment in the skill development program.

\section{Employers Readiness}

With the trivial and ongoing assault in some locations and dignitaries to PWD, efforts are being made by numerous agencies to make sure job placement is warranted for PWD. However, it is vital to reflect and obtain feedback from employers about their experience and readiness for hiring PWD. This group struggles in life and is feeling far from complacent about their job placement and survival. Because of this matter, some employers have become tremendously choosy and skeptical when hiring PWD. For example, Nurul (2017) denoted most employers in the hospitality industry, accepted people with hearing impairment. In addition, a study on employers' views on youth workers with disabilities by Yusof, Ali, and Salleh (2015) indicated that employers play an important role in creating job opportunities as well as providing encouragement to the disabled workforce. In this study, it is also stated that employers need to play an important role in ensuring that these disabled employees are comfortable, have fun, and are satisfied with their job.

A job associated with life survival and sustainability in earning. Hence, getting a job has become the primal factor to warrant stability in life. Contrastingly, there were bureaucracies and unfair processes of employment selection. According to Richard and Hennekam (2020) espoused the quota system effects are one of the major issues in hiring PWD. The decision of employing workers most likely is influenced by initiatives by the government in the form of tax exemption and incentives.

A previous study pointed out organizational readiness in accepting PWD in their company. Notably, the managerial behavior and positive attitudes towards accepting PWD will prosper their commitment to perform specific responsibilities and job tasks (Diab, Safan, \& Bakeer, 2018). Moore and Huberty (2020) on another note, stated that few employers invested in training and extension for temporary workers among those with disabilities and this further increased employment opportunities for PWD shall be appraised.

Additional understanding of employers' readiness is vital with a link to increase participation among PWDs in the workforce. Perception from negative connotation on readiness factors might deter the chances of PWDs although they have qualifications similar to other candidates. The judgmental sentiments are the most viable factor to disregard PWD's opportunities in getting suitable jobs. Hence, the extrinsic and intrinsic factors towards understanding employers' readiness are salient contributions to understand the situation. This includes 
accommodation, amenities, and psychological supports, as well as governance and policy in supporting PWDs' employment.

\section{Employers' Commitment}

The commitment of employers in hiring PWD drove social scientists to advocate a myriad scope of studies. Bonaccio et al. (2019) stated eleven concerns that employers have about people with disabilities. They recommend organizations committed to creating an effective and inclusive workplace for all individuals. The study of Romeo, Yepes-Baldó, and Lins (2020) involving 245 employees with different types of disabilities noted that the value of commitment was moderate in the relationship between intention and satisfaction with the supervisor relationship. In this context, a work culture based on people with disabilities is particularly important.

The study of Ramachandra et al. (2017) found that physical access at work sites was of concern to $95 \%$ of respondents. The majority of respondents argued that communication, people's attitudes, discrimination, harassment in the workplace, and information were critical barriers. Only $3.8 \%$ of employers are aware that their company has a written policy regarding employing people with disabilities. On another note, Tahir et al. (2020) found Malaysia's commitment to helping people with disabilities when the government ratified the United Nations (UN) Convention on the Rights of Persons with Disabilities and signed the Proclamation on Full Participation and Equality of Persons with Disabilities in Asia.

Koerber and Jennings's (2020) study of telephone access improvement strategies for the hearing impaired found several categories of telephone effectiveness strategies that support speech comprehension on the telephone and improve telephone skills as well as communication strategies in the workplace. In the study of Hashim et al. (2016, there was a positive relationship between organizational commitment and human resource management. Meanwhile, Aladwan, Bhanugopan, and D'Netto (2015) who conducted a study on relationships between organizational commitment with human resource management practices involving selection and recruitment showed a significant positive relationship to the three types of organizational commitment. Organizational commitment with recruitment practices has a positive relationship in the research conducted by Suriani (2015).

PWD employment can also be influenced negatively as a result of a lack of commitment by the employers. Notably, the lack of commitment in recruiting PWDs hampers their job chances in the organization. The adverse ecosystem and maltreatment from members of the organization have always become the cause of giving fair treatment to PWD. Commitment, in this sense, accumulates knowledge, belief, and values that need to be exercised in the organization that has PWD. Such commitments are pivotal to ensure the hired PWD possesses moral supports and ultimately strives and functions as productive employees similar to others.

\section{Employers' Disposition}

Several attempts have been made to understand employers' dispositions towards employees with disabilities. Among the studies is the study of Botha and Leah (2020) related to the attitude of public sector managers towards people with disabilities with a total of 283 respondents. This study found that managers are positive towards people with disabilities and these people with disabilities do not have unique characteristics compared to people without disabilities. The study also clarified that managers have a perception that people with these disabilities lack communication skills, technical skills, and social skills. 
Marzo Campos et al. (2020) related to the disposition of employers towards the entry of the workforce with borderline intellectual functioning showed a lack of knowledge about the characteristics of this type of disability. In addition, lack of empathy would hinder socialization within the company resulting in the low self-esteem of people with a lack of intellectual abilities. A similar study by Waugh et al (2017) which aimed to determine the attitudes towards mental illness who interviewed 24 healthcare professionals found that they have positive attitudes towards colleagues with mental illness. However, there were still quite a significant number of other professional health care providers who have had a negative attitude towards colleagues who have a mental illness. As professional healthcare, to have such skeptical perspectives towards PWD is unethical.

Smith et al. (2018) and Cheng et al. (2017) suggested clearer strategies such as natural support, employment support services, and instructional approaches to overcome this issue. It is notable, that such supports are important as a key determinant to empower PWDs' employment. A workplace environment that includes attitudes and the disposition of employers are predominant factors for PWDs. With the new ruling and government policy incusing intensive and benefits; yet to be a temptations reason for PWDS. Hence, the holistic approach including internal motivation plays a crucial decision in PWD's recruitment. PWDs are still struggling to join the workforce due to the pressure by industrial players that demand certain employment requirements (i.e., academic qualification, work experience, and type of disability). Notably, Smith et al. (2018) claimed that the provision of natural support to PWDs can lead to better employment opportunities for them because it can boost the confidence and self-esteem of PWDs for them to feel more at ease in an organization. They will feel appreciated and valued and in return, they will provide the best service in line with the trust and support given by the organization.

\section{Methodology}

The research employed descriptive survey research. The questionnaire consisted of three main variables: readiness, commitment, and disposition which was distributed to 148 employers from various industrial sectors in the state of Terengganu, Malaysia. The sample was derived from a random sampling technique from 240 employers. Due to the pandemic of COVID-19, the location of the study was chosen due to accessibility to obtain as many respondents that would be able to involve in this research. 136 employers $(91.89 \%)$ answered the questionnaire completely. The instrument used for this study was adopted from the perspectives of U.S. employers, which was also published online (Domzal, Houtenville, \& Sharma, 2008). The questionnaire was translated to the Malay language based on the perception that the meaning and transferability of the terms used in the instrument were easily understandable. The scale used in this study instrument is a 5 -point Likert scale and the instrument used is divided into five sections (Table 1).

Table 1. Instrumentation

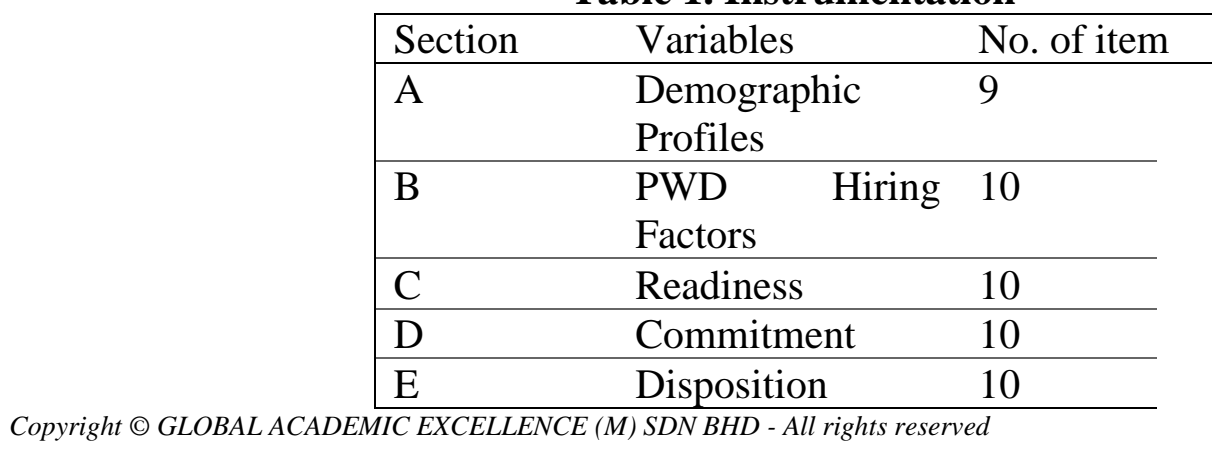


Section A consists of nine items involving the demographics of respondents and the recruitment of people with disabilities in work organizations. For the demographics of respondents, there are seven items namely gender, age, race, type of occupation, position in the workplace, number of disabled people working, and type of disabled person. The next two items are the factors taken into account in selecting PWDs fro workforce and reasons for not hiring PWDs in the organization. In section B, C, D, and E, there are 40 items all together which comprise of PWD hiring factors, employers' readiness, commitment, and disposition towards PWDs recruitment.

A pilot study on 30 respondents was conducted to determine the internal consistency of the instrument reliability. The characteristics and profiling of the pilot study respondents were similar to respondents with the actual study. The data obtained in the pilot study were analyzed statistically by reporting the value of the Cronbach Alpha coefficient. The reliability of the instrumentation was indicated at 0.67 . Table 2 was developed to scrutinize the reliability index for each variable. The value of the Cronbach Alpha coefficient for each of the variable depicts: (a) PWD hiring factors, 0.63, (b) employer readiness, 0.86, (c) employer commitment, 0.79, and (d) employer attitude, 0.61 . The reliability coefficient was confirmed with Pallant (2001) in Idris (2013) who justified that an alpha value of above 0.5 is considered good when the number of items in each section is not more than ten. Table 2 shows the values of Cronbach Alpha coefficients for the variables for the pilot study.

Table 2. Cronbach Alpha Values

\begin{tabular}{lc}
\hline Variables & Reliability Index (Pilot) \\
\hline PWD Hiring Factors & .631 \\
Employers' Readiness & .866 \\
Employers' Commitment & .797 \\
Employers' Disposition & .611 \\
\hline
\end{tabular}

\section{Demographic Profiles}

This study involves 136 out of 240 employers in Terengganu. The demographic profile of respondents consists of gender, age, race, position in the workplace, types of industry, number of PWD, types of disability, PWD hiring factors, and reasons to exclude PWD from job placement. Overall, the study respondents comprised $45.6 \%$ males and $54.4 \%$ females. In terms of age, $36.8 \%$ of respondents are between 20 years and 30 years old, $41.9 \%$ between 30 and $40,18.4 \%$ between 40 and 50 years, and $2.9 \%$ respondents between 50 years old and above. Of 136 respondents, a total of $120(88.2 \%)$ respondents is Malay, $14(10.3 \%)$ Chinese and 2 $(1.5 \%)$ Indian. For the position in the workplace, the majority of the respondents $(69.1 \%)$ are business owners, $5.9 \%$ managers, $2.9 \%$ supervisors, $7.4 \%$ shop assistants, and $14.7 \%$ posted as others. In addition, types of industry run by the respondents are services $41.2 \%$, apparel $9.6 \%$, food and beverages $40.4 \%$, art and craft $4.4 \%$, and other types of industries accumulate $4.4 \%$. Additionally, a total of $97.1 \%$ of employers stated no disabled employees in their organization and $2.9 \%$ of employers had at least one disabled employee in their organization. The types of disability of those who are working in the organizations are $2.2 \%$ slow learner and $0.7 \%$ deaf or hearing impairments, while $97.1 \%$ have no employees with any form of disabilities. The findings also report that the majority of the employers (34.6\%) agree that the source of employment information for PWDS is coming from the local rehabilitation and community center endorsement. Job advertisements $(12.5 \%)$ and references from friends $(11.8 \%)$ as well as colleague referrals (11.8\%) are among the important sources of seeking PWD who are ready to enter employment. 
Table 3. Demographic Findings

\begin{tabular}{|c|c|c|}
\hline Item & Frequency $(f)$ & Percentage $(\%)$ \\
\hline \multicolumn{3}{|l|}{ Gender } \\
\hline Male & 62 & 45.6 \\
\hline Female & 74 & 54.4 \\
\hline \multicolumn{3}{|l|}{ Age } \\
\hline $20-30$ & 50 & 36.8 \\
\hline $30-40$ & 57 & 41.9 \\
\hline $40-50$ & 25 & 18.4 \\
\hline 50 and above & 4 & 2.9 \\
\hline \multicolumn{3}{|l|}{ Race } \\
\hline Malay & 120 & 88.2 \\
\hline Chinese & 14 & 10.3 \\
\hline Indian & 2 & 1.5 \\
\hline \multicolumn{3}{|l|}{ Position } \\
\hline Business Owner & 94 & 69.1 \\
\hline Manager & 8 & 7.4 \\
\hline Supervisor & 10 & 5.9 \\
\hline Shop Assistant & 4 & 2.9 \\
\hline Other & 20 & 14.7 \\
\hline \multicolumn{3}{|l|}{ Number of PWD in organization } \\
\hline None & 132 & 97.1 \\
\hline 1 person & 4 & 2.9 \\
\hline More than 1 person & 0 & 0 \\
\hline \multicolumn{3}{|l|}{ Types of the employee with a disability } \\
\hline Physical & 0 & 0 \\
\hline Deaf or hearing impairment & 1 & 0.7 \\
\hline Slow learner & 3 & 2.2 \\
\hline No employee with a disability & 132 & 97.1 \\
\hline \multicolumn{3}{|l|}{ Source of PWD employment } \\
\hline Reference from colleagues & 16 & 11.8 \\
\hline Reference from friends & 16 & 11.8 \\
\hline Job advertisement & 17 & 12.5 \\
\hline State and Federal Government & 9 & 6.6 \\
\hline Rehabilitation or community center & 47 & 34.6 \\
\hline Others & 31 & 22.8 \\
\hline
\end{tabular}

$* \mathrm{n}=136$ 


\section{Reasons for Not Hiring PWD in The Organization}

Table 4 presents employers' reasons for not hiring PWD in their organizations. Unqualified candidates $(29.4 \%)$ set the main reason for employers' exclusion on hiring PWD. The second reason is discomforting among other employees within the organization with $18.4 \%$. Employers are also concerned about the cost of providing facilities to disabled employees $(17.6 \%)$ and since there are no available job vacancies $(17.6 \%)$, it is therefore difficult for job placement among PWD. Finally, about $16.9 \%$ fall under other undisclosed reasons, contributing to hiring PWD becomes more difficult.

Table 4. Reasons for Not Hiring PWD in Organization

\begin{tabular}{lcc}
\hline Reason & $\begin{array}{c}\text { Frequency } \\
(\boldsymbol{f})\end{array}$ & $\begin{array}{c}\text { Percentage (\%) } \\
\text { No Vacancy }\end{array}$ \\
$\begin{array}{l}\text { Unqualified candidates } \\
\text { Concerns related to the cost of providing facilities for }\end{array}$ & 40 & 17.6 \\
employees with disabilities & 24 & 29.4 \\
Discomfort to other employees due to the presence of & 25 & 17.6 \\
PWD & 23 & 18.4 \\
Others & & 16.9 \\
\hline
\end{tabular}

\section{Employers' Readiness for PWD Recruitment}

Table 5 describes items related to the employer's readiness to recruit employees among PWD. Based on the total mean of 4.10 with a standard deviation of 0.69 , the majority of the respondents are ready to hire PWD to work in their organization. The highest mean was set at 4.52 with the item "[m]y organization exercises freedom of speech and opportunity to voice out issues and problems related to PWD employment". The least of readiness items fall into two statements with the same mean value of 3.72 are "[m]y organization aware on policy and guideline in hiring PWDs for employment" and "[m]y organization provides necessary facilities for PWD such as spacious parking lot and PWD-friendly workstation".

Table 5. Descriptive Analysis of Employers' Readiness on Hiring PWD for Employment.

\begin{tabular}{clccc}
\hline No & \multicolumn{1}{c}{ Item } & M & SD & Scale \\
\hline 1. & $\begin{array}{l}\text { My organization is willing to hire PWD for } \\
\text { employment at any time. }\end{array}$ & 3.76 & 1.16 & High \\
2. $\quad \begin{array}{l}\text { My organization will enjoy tax relief if the hiring } \\
\text { process of PWD is successful. } \\
\text { 3. }\end{array} \quad \begin{array}{l}\text { My organization is aware of policy and } \\
\text { guidelines in hiring PWDs for employment. } \\
\text { My organization provides necessary facilities for } \\
\text { PWD such as a spacious parking lot and PWD- }\end{array}$ & 3.72 & 1.72 & High \\
& $\begin{array}{l}\text { Priendly workstation. } \\
\text { My organization can provide job training for an } \\
\text { employee with disabilities. }\end{array}$ & 4.40 & 0.69 & High \\
5. & High
\end{tabular}


6. My organization celebrates diversity and inclusion policy for PWD employment.

$4.17 \quad 0.98$

High

7. My organization provides mentoring initiatives to assist PWD in fulfilling the job responsibility.

8. My organization has zero tolerance for rudeness and disrespect among employees towards PWD.

9 My organization exercises freedom of speech and the opportunity to voice out issues and problems related to PWD employment.

10 My organization is ready to provide affordable and accessible transportation services for PWD

\section{$3.94 \quad 1.30 \quad$ High}

$4.29 \quad 1.01 \quad$ High

$\begin{array}{lll}4.52 & 0.77 \quad \text { High }\end{array}$

$4.17 \quad 0.85 \quad$ High

\section{Employer's Commitment for PWDS Recruitment}

Table 6 reveals employers' commitment to hiring PWD. Even though the total of the mean values depicts high with 4.07, several items show the important fact of less commitment of hiring PWD. It is quite revealing that, yet some employers are still refusing to hire PWD. The item "[m]y organization hesitant on having PWD working in the company employers' implicates a minority group of employers' decisions on the hiring process. Of 10 items, "[m]y organization creates a positive working environment by integrating employees with or without disability" scores the highest mean value with 4.41 with a standard deviation of 0.69 .

Table 6. Descriptive Analysis of Employers' Commitment to Hiring PWD for Employment.

\begin{tabular}{clccc}
\hline No & \multicolumn{1}{c}{ Statement } & M & SD & Scale \\
\hline 1. & $\begin{array}{l}\text { My organization ensures knowledge } \\
\text { management is fair to all employees with } \\
\text { or without disabilities. }\end{array}$ & 4.35 & 0.76 & High
\end{tabular}

2. My organization is hesitant about having PWD working in the company

$3.47 \quad 1.38 \quad$ Medium

3. My organization places a lack of effort in hiring PWD.

3.70 $1.07 \quad$ High

4. It has become a practice in my organization to form a support group for PWD.

$3.82 \quad 1.10 \quad$ High

5. My organization ensures fair and equal opportunity to PWD

4.17 $0.70 \quad$ High

6. My organization is committed to ensuring a safe and inclusive working environment to uphold the welfare of disabled people.

4.01 $0.95 \quad$ High


7. My organization shares the company goals and mission to employ PWD.

$4.12 \quad 0.88$

High

8. The employees exercise positive values and attitudes to PWD

4.35 $0.68 \quad$ High

9. The employees in my organization celebrate the differences of PWD

$4.35 \quad 0.68 \quad$ Medium

10. My organization creates a positive working environment by integrating employees with or without disability

Overall Average

$4.41 \quad 0.69$

Medium

\section{Employer's Disposition on Hiring PWD}

Table 7 indicates the value of the mean and standard deviation of items related to employers' disposition on hiring PWD. It is apparent from this table that several negative items contribute to the lowest mean for example "[h]iring employee with disabilities will become a burden to other employees," $(\mathrm{M}=2.77, \mathrm{SD}=1.32)$ and "I have less confidence in giving job responsibility to PWD ( $\mathrm{M}=2.58, \mathrm{SD}=1.17)$. Although the mean values represent the small group of respondents, yet it contributes to the total mean which is set at 3.55. This result exhibits the disposition of employers on hiring PWD places at a medium level. Nevertheless, the highest mean on item 2 shows that "PWD has the right to request for employment in my organization" with $(\mathrm{M}=4.47, \mathrm{SD}=0.50)$.

Table 7. Descriptive Analysis of Employers' Disposition on Hiring PWD For Employment.

\begin{tabular}{clrllllll}
\hline No. & & Item & & & M & SD & Scale \\
\hline 1. & $\begin{array}{l}\text { My organization } \\
\text { employment }\end{array}$ & will & hire & PWD & for & & & \\
& & & & 4.35 & 0.68 & High
\end{tabular}

2. PWD has the right to request employment in my organization

4.47 $\quad 0.50 \quad$ High

3. Employees with disabilities should obtain certain privileges in the workplace such as special parking spots and pathways to the

4.41 $0.69 \quad$ High
workstation.

4. I have less confidence in giving job responsibility to PWD

$2.58 \quad 1.17 \quad$ Medium

5. I am ready to renovate and remodel the workplace to accommodate the needs of PWD.
4.13
0.76
High

6. The work performance of PWD is similar to other employees

$3.94 \quad 1.00 \quad$ High


7. An employee with some form of disabilities should be paid less compared to other employees

$2.62 \quad 1.34 \quad$ Medium

8. Hiring employees with disabilities will become a burden to other employees.

$2.46 \quad 1.32 \quad$ Medium

9. I am responsible to hire and supervise PWD in my organization

$3.76 \quad 1.11 \quad$ High

10. My organization discriminates against PWD involvement in employment

$2.77 \quad 1.43 \quad$ Medium

Overall Average

$3.55 \quad 0.47 \quad$ Medium

\section{Factors on Hiring PWD}

It appears from table 8 that the overall mean for factors on hiring PWDS is 3.69 with a standard deviation of 0.58. Employers would appreciate those PWD who are capable of fulfilling specific tasks, indicating the highest mean of 4.24 with a standard deviation of 0.88 . The last factor is by hiring PWD will produce discomfort among customers and clients with $(\mathrm{M}=2.48$, $\mathrm{SD}=1.27)$

Table 8. Descriptive Analysis of Factors Towards Hiring PWD For Employment

\begin{tabular}{clccc}
\hline No & \multicolumn{1}{c}{ Statement } & M & SD & Scale \\
\hline 1. & $\begin{array}{l}\text { Double tax deduction for investment } \\
\text { spent on PWD workforce training. }\end{array}$ & 4.11 & 1.01 & High \\
\hline & & 4.11 & 1.07 & High
\end{tabular}

2. Tax relief for successful employment among PWD

3. The training cost for PWD is funded by $4.04 \quad 1.11 \quad$ High the government and interested agencies.

4. Hiring PWD will portray a positive 4.16 $1.05 \quad$ High image of your organization in terms of social responsibility

5. $\quad$ PWD are hiring due to their capability $4.24 \quad 0.88 \quad$ High and capacity to fulfilling job responsibilities

6. The working environment in my $2.79 \quad 1.36$ organization does not accommodate the Medium needs of PWD

7. $\quad$ Hiring PWDs will produce discomfort to $2.48 \quad 1.27 \quad$ Medium customers and clients.

8. My organization has a significant $3.26 \quad 1.25 \quad$ Medium partnership with government and non- 
government agencies in empowering

PWD employment.

\begin{tabular}{lllll}
\hline 9. & $\begin{array}{l}\text { My organization takes less effort to hire } \\
\text { PWD for employment. }\end{array}$ & 3.47 & 1.14 & Medium \\
\hline 10. & $\begin{array}{l}\text { My organization will receive a discount } \\
\text { on tax for any renovation and remodeling } \\
\text { costs to accommodate the needs of the } \\
\text { employee with a disability. }\end{array}$ & 0.87 & High \\
\hline Overall Mean & 3.69 & 0.58 & High \\
\hline
\end{tabular}

\section{Correlation Analysis Between Readiness, Commitment, Disposition of Employers, and PWD Hiring Factors}

Table 9 shows the results of Pearson Correlation Analysis to determine the relationship between employer readiness, commitment, and disposition on employer hiring factors. The correlations between readiness, commitment and hiring factors were found to be weakly positively correlated, $r(134)=.25, p=.03$ and $r(134)=.37, p=.00$ respectively. The correlation between disposition and hiring factors were found to be moderately positively correlated, $r(134)=.68, p=.00$.

Table 9. Readiness, Commitment, And Disposition of Employers on Hiring Factors Variable PWD Hiring Factors

Strength of correlation

\begin{tabular}{lccc}
\cline { 2 - 3 } & $\begin{array}{c}\text { Correlation } \\
\text { coefficient }(r)\end{array}$ & $p$ & \\
\hline Employer's readiness & .25 & 0.03 & Weak \\
Employer's commitment & .37 & 0.00 & Weak \\
Employer's disposition & .68 & 0.00 & Moderate \\
\hline
\end{tabular}

Note. $\mathrm{N}=136$, correlation is significant at a 0.01 ( 2 tailed)

\section{ANOVA Analysis Between Types of Industry and Employers' Readiness, Commitment, Disposition on Hiring PWD}

One-way analysis of variance between-subjects ANOVA was conducted to compare the effect of types of industry on employers' readiness, commitment, and disposition. The types of the industries involved in this study were There was a significant relationship between types of industry $\mathrm{p}<.05$ level for readiness and commitment with $(\mathrm{F} 4,131=8.724 ; \mathrm{p}>.05)$ and $(\mathrm{F} 4,131$ $=7.547 ; \mathrm{p}>.05)$ respectively. However, the ANOVA analysis between types of industry and employer's disposition did not significantly differ from both variables $(F 4,131=1.071 ; p>.05)$. Taken together, these results suggest that types of industry play a significant effect on employers' readiness and commitment to hiring PWD. The relationship between types of industry and employers' dispositions, on the other hand, describes vice versa. The details of the findings are stated in the following tables: 
Volume 4 Issue 15 (September 2021) PP. 01-22

DOI: 10.35631/IJEMP.415001

Table 10. ANOVA Test Analysis on Employer Readiness, Commitment, And Readiness by Types of Industry

\begin{tabular}{|c|c|c|c|c|c|c|}
\hline Predictor & & $\begin{array}{l}\text { Sum of } \\
\text { Squares }\end{array}$ & $\begin{array}{l}\text { Degrees } \\
\text { of } \\
\text { Freedom } \\
\text { (df) }\end{array}$ & $\begin{array}{c}\text { Mean } \\
\text { Squared }\end{array}$ & $\begin{array}{l}\text { The } \\
\text { value } \\
\text { of } F\end{array}$ & Significant \\
\hline \multirow[t]{2}{*}{ Readiness } & $\begin{array}{l}\text { Between } \\
\text { Groups }\end{array}$ & 13.828 & 4 & 3.457 & 8.724 & $.000^{*}$ \\
\hline & In Group & 51.910 & 131 & .396 & & \\
\hline \multirow[t]{2}{*}{ Commitment } & $\begin{array}{l}\text { Between } \\
\text { Groups }\end{array}$ & 8.636 & 4 & 2.159 & 7.547 & $.000 *$ \\
\hline & In Group & 37.472 & 131 & .286 & & \\
\hline \multirow[t]{2}{*}{ Disposition } & $\begin{array}{l}\text { Between } \\
\text { Groups }\end{array}$ & .966 & 4 & .242 & 1.071 & .374 \\
\hline & In Group & 29.552 & 131 & .226 & & \\
\hline
\end{tabular}

*Note. significant at $\mathrm{p}<0.05$

Table 11. Employers' Readiness Score Distribution Based on Types Of Industry

\begin{tabular}{cccc} 
Types of Industry & $(\mathbf{N})$ & Mean & Standard Deviation \\
\hline Services & 56 & 4.010 & .764 \\
Apparel & 13 & 3.938 & .497 \\
Food \& Beverages & 55 & 4.407 & .495 \\
Crafts & 6 & 3.000 & .000 \\
Others & 6 & 3.783 & .837 \\
\hline Total & 136 & 4.109 & .697 \\
\hline
\end{tabular}

Table 12. Post-Hoc Scheffe Test Results Between Readiness and Types of Industry Types of Industry $\quad$ Mean difference Standard error $p$

\begin{tabular}{|ccccc}
\hline Services & Apparel & .072 & .193 & .996 \\
\hline Services & Food \& Beverages & -.398 & .119 & $.010^{*}$ \\
\hline Services & Crafts & 1.017 & .270 & $.003^{*}$ \\
\hline Services & Others & .227 & .270 & .917 \\
\hline Apparel & Food \& Beverages & -.468 & .194 & .118 \\
\hline
\end{tabular}


Volume 4 Issue 15 (September 2021) PP. 01-22

DOI: 10.35631/IJEMP.415001

\begin{tabular}{|clccc}
\hline Apparel & Crafts & .938 & .310 & $.025^{*}$ \\
\hline Apparel & Others & .1551 & .310 & .987 \\
\hline Food \& Beverages & Crafts & 1.407 & .270 & $.000^{* *}$ \\
\hline Food \& Beverages & Others & .623 & .270 & .150 \\
\hline Crafts & Others & -783 & .363 & .203 \\
\hline
\end{tabular}

$*$ Note. significant at $\mathrm{p}<0.05$

$* *$ Note. significant at $\mathrm{p}<0.00$

Table 13. Employers' Commitment Score Distribution Based on Types Of Industry Types of Industry Sample Mean Standard Deviation

\begin{tabular}{cccc}
\hline Services & 56 & 4.025 & .659 \\
Apparel & 13 & 3.938 & .333 \\
Food \& Beverages & 55 & 4.305 & .422 \\
Crafts & 6 & 3.233 & .081 \\
Others & 6 & 3.650 & .712 \\
\hline Total & 136 & 4.078 & .584 \\
\hline
\end{tabular}

\begin{tabular}{|ccccc}
\hline \multicolumn{4}{|c}{ Table 14. Post-Hoc Scheffe Test Results Between Commitment and Types of Industry } \\
\hline \multicolumn{2}{c}{ Types of Industry } & Mean Difference & Standard error & $p$ \\
\hline Services & Apparel & .086 & .164 & .985 \\
\hline Services & Food \& Beverages & -.280 & .101 & .051 \\
\hline Services & Crafts & .791 & .229 & $.007 * *$ \\
\hline Services & Others & .375 & .229 & .480 \\
\hline Apparel & Food \& Beverages & -.366 & .164 & .177 \\
\hline Apparel & Crafts & .705 & .263 & .064 \\
\hline Apparel & Others & .288 & .263 & .810 \\
\hline Food \& Beverages & Crafts & 1.072 & .229 & $.000^{* *}$ \\
\hline Food \& Beverages & Others & .655 & .229 & $.040^{*}$ \\
\hline
\end{tabular}




\begin{tabular}{lllll}
\hline Crafts & Others & -.416 & .308 & .661 \\
\hline
\end{tabular}

*Note. significant at $\mathrm{p}<0.05$

**Note. significant at $\mathrm{p}<0.00$

Table 15. Employers' Disposition Score Distribution Based on Types of Industry

\begin{tabular}{cccc} 
Types of Industry & $(\mathbf{N})$ & Mean & Standard Deviation \\
\hline Services & 56 & 3.583 & .602 \\
Apparel & 13 & 3.746 & .345
\end{tabular}

Food \& Beverages $\quad 55 \quad 3.472 \quad .311$

\begin{tabular}{cccc} 
Crafts & 6 & 3.500 & .000 \\
Others & 6 & 3.650 & .763 \\
\hline Total & 136 & 3.553 & .475 \\
\hline
\end{tabular}

\begin{tabular}{|ccccc}
\hline \multicolumn{5}{c}{ Table 16. Post-Hoc Scheffe Test Results Between Disposition and Types of } \\
Industry \\
\hline Types of Industry & Mean Difference & Standard error & $p$ \\
\hline Services & Apparel & -.162 & .146 & .801 \\
\hline Services & Food \& Beverages & .111 & .090 & .732 \\
\hline Services & Crafts & .083 & .204 & .994 \\
\hline Services & Others & -.066 & .204 & .998 \\
\hline Apparel & Food \& Beverages & .273 & .146 & .340 \\
\hline Apparel & Crafts & .246 & .234 & .831 \\
\hline Apparel & Others & .096 & .234 & .994 \\
\hline Food \& Beverages & Crafts & -.027 & .204 & 1.000 \\
\hline Food \& Beverages & Others & -.177 & .204 & .908 \\
\hline Crafts & Others & -.150 & .274 & .982 \\
\hline & & & & \\
\hline & & & & \\
\hline
\end{tabular}




\section{Discussion}

The objective of the present work is to distinguish employers' perspectives on hiring people with disabilities from three factors: readiness, commitment, and disposition. These three factors are the determinant factors for this study to extant the works from scholarly researchers who worked within a similar research context. PWD are the groups who suffered injustice and struggles for many years. Due to their impairment and disability, many of them struggle to enjoy the wealth of the country, especially earning income from their involvement in the workforce. The results spelled out the role of employers in selecting and hiring employees among PWDs. Cohen et al. (2019) indicated that employers value work performance from the efforts of their employees, on the contrary, it becomes a barrier for PWDS entering the labor market. For the reason that employers value rapid and mass production to maximize profits for the organization, hiring PWDs may delay the objective and the mission of the company objectifying mass output for the company. Notably, this ecosystem becomes an obstacle for employers who have PWD in their organizations to continue the business.

The findings of the study, however, reveals significant findings on employers' intention on hiring PWD. The study also reports that a few of the employers refuse to hire PWD due to some reason. Selected factors such as less confidence in PWD and fear of PWD existent will contribute to burden to others are those reasons that trigger PWD exclusion in the employment market. Many researchers found similar results as the hindrance factors towards hiring PWD. Research findings by Nurul (2017) showed that the level of acceptance of the hospitality industry towards workers with special needs (hearing impairment) is at a moderate level. This explains that people with disabilities still have less of a place in employment organizations. The willingness of employers in ensuring job placement for PWD is still undoubtedly posing a question. Although numerous researchers have pointed out the importance of having a job for PWD, there has been limited practical implication towards solving the issue.

An effort is precipitated by the negative connotation of such individuals who portray a negative perception of PWD. Hence, industrial players should be open and more receptive to allowing PWD to venture employment (Yusof, Ali, \& Salleh, 2015) Employers are a pillar of organizational change and this allows employers to be prepared in selecting and PWD in their organizations. In addition, employers can change organizational policies to accommodate the needs of PWD. Diab, Safan, and Bakeer (2018) suggest organizations need to have a readiness for change to support the process by having the right resources and conditions as well as goals for change. As an employer, the use of existing resources can assist employers in selecting employees from among people with disabilities and change the goals of the organization by making people with disabilities as employees in the organization.

In addition, employers need to be prepared to open quotas to people with disabilities in the organization as well as make changes by providing opportunities for people with disabilities to stand out in discussions and listen to their opinions in improving work and organizational performance. According to Richard and Hennekam (2020), individuals can be strategists with a quota system. As people with disabilities, their views should also be heard in the organization, and this can help the organization empower employees among people with disabilities. Leadership practices and organizational climate change increase organizational readiness for change (von Treuer et al., 2018). Employers who are willing to make changes in leadership and organizational climate to take people with disabilities to work are employers with a high willingness to change. 
However, a study by Oware and Mallikarjunappa (2019) shows that significant arguments do exist, albeit findings are somewhat contradictory from numerous studies. They claimed that employees with disabilities help improve a firm's financial performance due to the presence of innovation in technology. With the help of technology and optimizing loads of PWDs by placing responsibilities that ensemble their categories of disability, PWDs can be given a job that helps them gain income. On that account, employers need to integrate technology to help employees with disabilities improve job and organizational performance. Supports shall be made continuously by respective stakeholders especially the public and private sector to enforce this effort.

Encouragement factors from the government are also among the factors in the selection of employees among the disabled. The study of Tahir et al. (2020) found that laws enacted by the government can help people with disabilities in employment. Some policies to ensure people with disabilities also encourage employers to hire employees among people with disabilities. Various programs can be carried out between employers in collaboration with associations of people with disabilities so that knowledge sharing in the employment industry can help improve the skills of people with disabilities. In addition, employers can employ people with disabilities as a result of this cooperation program.

Employers' commitment to understanding the capabilities and capabilities of employees with disabilities by providing convenient access to employees with disabilities. Koerber and Jennings (2020), found that these telephone facilities provide access to hearing-impaired employees and potentially benefit employees and employers. Ramachandra et al. (2017), showed employers are committed to hiring people with disabilities and they are diligent in being facilitators to people with disabilities. Employers are the pillars of an organization and the diligence and commitment of employers in helping employees with disabilities in this work provide opportunities for people with disabilities to improve their skills in a field. In short, employers 'commitment to selecting and employing people with disabilities is a motivator for people with disabilities to work hard within the organization and be competitive with other colleagues. Employer commitment is an important aspect in selecting employees from among people with disabilities.

Employer attitudes play a role in selecting and employing employees among people with disabilities. This discriminatory and prejudicial attitude of employers about people with disabilities makes it difficult for people with disabilities to get a job (Anwar et al., 2020). This discriminatory attitude needs to be corrected to suit the times and this attitude makes it difficult for people with disabilities to get employment opportunities, especially in rural areas. According to Thanapalan, Murad, and Natar (2016), stigma against individuals with mental illness is less when compared to stereotypes, limitations, and virtues. Employers' stereotypical attitudes are high because of the culture and beliefs in their environment. The stereotypes that exist in the culture of this society need to be corrected in ensuring that people with disabilities are not oppressed in employment. In short, the attitude of the employer to play an important role in the organization and also the negative attitude is shown by the employer towards the disabled should be removed and the employer should be supportive in empowering the disabled in employment.

The research implies a significant contribution to policymakers and curriculum development at the ministry level to enhance job opportunities for PWD. The networking between educational stakeholders and job providers should be strengthened in such a way that PWDs Copyright (C) GLOBAL ACADEMIC EXCELLENCE (M) SDN BHD - All rights reserved 
are more likely to gain attention from various stakeholders. Programs and activities at different levels should be carried out inclusively within the participation of PWD. The government and private agencies play a significant role in organizing programs activities that can promote PWD participation in job markets which will simultaneously portray positive perceptions to this group of people. Additionally, ongoing supports should be promoted in a knowledge transfer program and sharing session which subsequently flourish mutual understanding between industrial players and PWD training providers in meeting up the demands.

Reflecting on theoretical implication, the findings reaffirmed the contribution of readiness and commitment as pillars to encourage participation among PWDs in the workforce. The mentioned variables were found significant factors to justify employers' perception of hiring PWDs. Ample researches supported the benefactor determinants towards the likelihood of employers recruiting PWDs were mainly internal factors that proven adaptable within the capacity and capability of PWDs. Future research on the inductive approach via qualitative study will trigger imperative evidence on the reality of the job market and deniable details on PWDs narratives.

\section{Conclusion}

This research set out to determine the relationship between employers' readiness, commitment, and disposition and hiring factors of PWD in the workforce. The primary goal is to determine employers' perspectives on perceiving PWD as part of their organizational employees which sequentially empowers PWD for employment. The study has found that generally, employers are supporting in hiring PWD into their company. Although support in the form of extrinsic values such as tax relief and training funds has subjugated the company's decision on hiring PWD, the government policy also brought into the improvement of PWD employment in the nation. There are cynical and skeptical views on the ability of the disabled to perform certain duties and responsibilities. Some consider the disabled to be a burden and unproductive. As a result, they continue to be marginalized from obtaining better employment opportunities. Often the potential and talents of the disabled are not highlighted to the proper level. This problem will contribute to unemployment among the disabled, especially in rural areas. The lack of indifference among the community towards the disabled causes them to continue to drift with problems that can be overcome and addressed at an early stage. Stakeholders need to refine and formulate strategies to strengthen the contribution of PWDs in various fields that have the potential for them to venture into. Thus, future research on PWD skill and training empowerment shall be addressed to mitigate the employment needs. Reskilling and upskilling shall be mandated to PWD; hence talent and skill development can be prospered then eventually will flourish the life of PWD holistically.

\section{Acknowledgments}

This study was funded by the Malaysian Ministry of Education (FRGS/1/2019/SSI09/UPM/02/3) from the Fundamental Research Grant Scheme (FRGS). Appreciation also goes to Universiti Putra Malaysia (UPM), Research Management Centre (RMC), and the Innovative Learning Sciences Research Centre of Excellence (INNOVATE), UPM for the coordination and distribution of financial support for this study. 


\section{References}

Aladwan, K., Bhanugopan, R., \& D'Netto, B. (2015). The effects of human resource management practices on employees' organisational commitment. International Journal of Organizational Analysis (2005), 23(3), 472-492. https://doi.org/10.1108/IJOA-11-2014-0822

Anwar, F. N. D. H. N., \& Ullah, T. I. (2020). Difficulties Faced by the Persons with Disabilities for Getting Employment. Retrieved May $11^{\text {th }}$, 2021 from https://pssr.org.pk/issues/v4/2/difficulties-faced-by-the-persons-with-disabilities-forgetting-employment.pdf

Bezyak, J., Moser, E., Iwanaga, K., Wu, J. R., Chen, X., \& Chan, F. (2020). Disability inclusion strategies: an exploratory study. Journal of Vocational Rehabilitation, (Preprint).

BLS (2021). Persons With A Disability: Labor Force Characteristics - 2020. Retrieved April $13^{\text {th }}, 2021$ from https://www.bls.gov/news.release/pdf/disabl.pdf

Bonaccio, S., Connelly, C., Gellatly, I., Jetha, A., \& Martin Ginis, K. (2020). The Participation of People with Disabilities in the Workplace Across the Employment Cycle: Employer Concerns and Research Evidence. Journal of Business and Psychology, 35(2), 135158. https://doi.org/10.1007/s10869-018-9602-5

Botha, P., \& Leah, L. (2020). Exploring public sector managers' attitudes towards people with disabilities. SA Journal of Human Resource Management, 18(14), e1-e10. https://doi.org/10.4102/sajhrm.v18i0.1421

CDC (2020). Disability Impacts All of Us. Retrieved April 13 ${ }^{\text {th }}, 2021$ from https://www.cdc.gov/ncbddd/disabilityandhealth/infographic-disability-impactsall.html

Cheng, C., Oakman, J., Bigby, C., Fossey, E., Cavanagh, J., Meacham, H., \& Bartram, T. (2017). What constitutes effective support in obtaining and maintaining employment for individuals with intellectual disability? A scoping review. Journal of Intellectual \& Developmental Disability, 43(3), 317-327.doi:10.3109/13668250.2017.1327040

Cohen, J., Schiffler, F., Rohmer, O., Louvet, E., \& Mollaret, P. (2019). Is disability really an obstacle to success? Impact of a disability simulation on motivation and performance. Journal of Applied Social Psychology, 49(1), 50-59.

Department of Statistics Malaysia (2020). Social Statistics Bulletin Malaysia 2018. Retrieved April 20 2021 from https://www.dosm.gov.my/v1/index.php?r=column/cthemeByCat\&cat=152\&bul_id= NU5hZTRkOSs0RVZwRytTRE5zSitLUT09\&menu_id=U3VPMldoYUxzVzFaYmN kWXZteGduZz09

Diab, G. M., Safan, S. M., \& Bakeer, H. M. (2018). Organizational change readiness and manager behavior in managing change. Journal of Nursing Education and Practice, 8(7), 68-77.

Domzal, C., Houtenville, A., \& Sharma, R. (2008). Survey of employer perspectives on the employment of people with disabilities: Technical report. Office of Disability Employment Policy, Department of Labor.

Emerson, E., Fortune, N., Aitken, Z., Hatton, C., Stancliffe, R., \& Llewellyn, G. (2020). The wellbeing of working-age adults with and without disability in the UK: Associations with age, gender, ethnicity, partnership status, educational attainment and employment status. Disability and Health Journal, 13(3), 100889-100889. https://doi.org/10.1016/j.dhjo.2020.100889

Hashim, A., Zolkifli, N., Othman, N., \& Mustapha, N. H. (2016). Hubungan amalan pengurusan sumber manusia dan komitmen organisasi. In Proceeding of the 2nd International Conference on Economics \& Banking (pp. 262-273). 


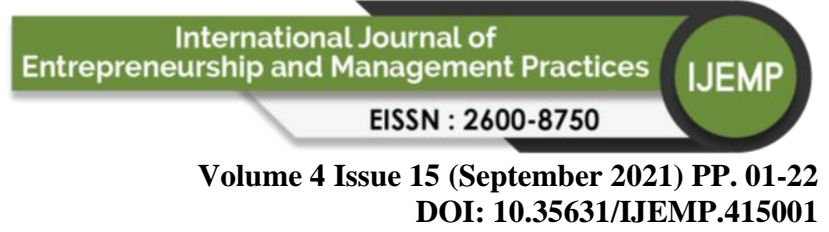

Idris, N. (2013). Penyelidikan dalam pendidikan. McGraw-Hill Education.

Kochel, A. L. (2002). Small business needs for information regarding the employment of people with disabilities. Master thesis. University of Wisconsin, USA.

Koerber, R., \& Jennings, M. B. (2020). Increasing telephone accessibility for workers with hearing loss: a scoping review with recommendations. International Journal of Audiology, 59(10), 727-736.

Marzo Campos, J., López Sánchez, M., Martínez-Pujalte López, A., \& Ramos López, M. (2020). Employers' attitudes towards labour inclusion of persons with borderline intellectual functioning (BIF): An empirical evidence. Cogent Social Sciences, 6(1), 1723186-. https://doi.org/10.1080/23311886.2020.1723186

Moore M.E., Huberty L.L. (2020) Temporary Status in Work Organizations for People with Disabilities: An Opportunity or Barrier. In: Fielden S.L., Moore M.E., Bend G.L. (eds) The Palgrave Handbook of Disability at Work. Palgrave Macmillan, Cham. https://doi.org/10.1007/978-3-030-42966-9_16

Nicholas, D., Mitchell, W., Zulla, R., \& Dudley, C. (2019). Perspectives of employers about hiring individuals with autism spectrum disorder: Evaluating a cohort of employers engaged in a job-readiness initiative. Journal of Vocational Rehabilitation, 50(3), 353364. https://doi.org/10.3233/JVR-191018

Nurul. A. S., (2017). Persepsi industri hospitaliti terhadap golongan pekerja berkeperluan khas (masalah pendengaran) (Doctoral dissertation, Universiti Tun Hussein Onn Malaysia).

Oware, K., \& Mallikarjunappa, T. (2020). Disability employment and financial performance: the effect of technological innovation of listed firms in India. Social Responsibility Journal, ahead-of-print(ahead-of-print). https://doi.org/10.1108/SRJ-09-2019-0299

Ramachandra, S., Murthy, G., Shamanna, B., Allagh, K., Pant, H., \& John, N. (2017). Factors Influencing Employment and Employability for Persons with Disability: Insights from a City in South India. Indian Journal of Occupational and Environmental Medicine, 21(1), 36-41. https://doi.org/10.4103/ijoem.IJOEM_44_16

Richard, S., \& Hennekam, S. (2020). When Can a Disability Quota System Empower Disabled Individuals in the Workplace? The Case of France. Work, Employment and Society, 0950017020946672.

Romeo, M., Yepes-Baldó, M., \& Lins, C. (2020). Job Satisfaction and Turnover Intention Among People With Disabilities Working in Special Employment Centers: The Moderation Effect of Organizational Commitment. Frontiers in Psychology, 11, 10351035. https://doi.org/10.3389/fpsyg.2020.01035

Saidi, H. M., Amin, A. S., Aun, N. S. M., Selamat, M. N., \& Nor, M. I. H. M. (2018). Isu dan Cabaran Pekerjaan Orang Kurang Upaya Penglihatan di Malaysia (Employment Issues and Challenges of Persons with Visual Impairment in Malaysia). Jurnal Psikologi Malaysia, 32(4).

Smith, P., McVilly, K. R., McGillivray, J., \& Chan, J. (2018). Developing open employment outcomes for people with an intellectual disability utilising a Social Enterprise Framework. Journal of Vocational Rehabilitation, 48(1), 59-77.

Suriani A. B., (2015). Kajian Kes di Syarikat Philip Morris Malaysia (PMI) berkaitan Amalan Pengurusan Sumber Manusia dengan Komitmen Organisasi. Tesis. Universiti Utara Malaysia.

Tahir, Z., Thambapillay, S., Yusoff, J. Z. M., \& Rahman, A. S. A. (2020). Undang-undang berkenaan orang kurang upaya: Satu analisis perkembangan perundangan di Malaysia. The Malaysian Journal of Social Administration, 14(1), 96-114. 
Thanapalan, C., Murad, M., \& Natar, A. (2016). Work Environmental Support from Small Industry's Employer Perspectives for Workers with Mental Illness. Procedia, Social and Behavioral Sciences, 222, 423-431. https://doi.org/10.1016/j.sbspro.2016.05.203

The World Bank (2021). Disability Inclusion. Retrieved April 13 ${ }^{\text {th }}, 2021$ from https://www.worldbank.org/en/topic/disability

Unit, P. M. S. S. (2005). Improving the life chances of disabled people. London: Cabinet Office, 74 .

von Treuer, K., Karantzas, G., McCabe, M., Mellor, D., Konis, A., Davison, T., \& O’Connor, D. (2018). Organizational factors associated with readiness for change in residential aged care settings. BMC Health Services Research, 18(1), 77-77. https://doi.org/10.1186/s12913-018-2832-4

Wanita, K. P., \& dan Masyarakat, K. (2016). Pelan Tindakan OKU 2016-2022. KPWKM: Putrajaya

Waugh, W., Lethem, C., Sherring, S., \& Henderson, C. (2017). Exploring experiences of and attitudes towards mental illness and disclosure amongst health care professionals: a qualitative study. Journal of Mental Health (Abingdon, England), 26(5), 457-463. https://doi.org/10.1080/09638237.2017.1322184

Yusof, A., Ali, M., \& Salleh, A. (2015). Youth Workers with Disabilities: The Views of Employers in Malaysia. Procedia, Social and Behavioral Sciences, 204, 105-113. https://doi.org/10.1016/j.sbspro.2015.08.12 